University of Nebraska - Lincoln

DigitalCommons@University of Nebraska - Lincoln

\title{
Visual control of refuge recognition in the whip spider Phrynus marginemaculatus
}

Kaylyn A.S. Flanigan

Daniel D. Wiegmann

Patrick Casto

Vincent J. Coppola

Natasha R. Flesher

See next page for additional authors

Follow this and additional works at: https://digitalcommons.unl.edu/bioscihebets

Part of the Animal Sciences Commons, Behavior and Ethology Commons, Biology Commons, Entomology Commons, and the Genetics and Genomics Commons

This Article is brought to you for free and open access by the Papers in the Biological Sciences at DigitalCommons@University of Nebraska - Lincoln. It has been accepted for inclusion in Eileen Hebets Publications by an authorized administrator of DigitalCommons@University of Nebraska - Lincoln. 


\section{Authors}

Kaylyn A.S. Flanigan, Daniel D. Wiegmann, Patrick Casto, Vincent J. Coppola, Natasha R. Flesher, Eileen Hebets, and Verner Peter Bingman 


\title{
Visual control of refuge recognition in the whip spider Phrynus marginemaculatus
}

\author{
Kaylyn A. S. Flanigan, ${ }^{1,2}$ Daniel D. Wiegmann, ${ }^{2,4}$ \\ Patrick Casto, ${ }^{2,4}$ Vincent J. Coppola, ${ }^{5}$ \\ Natasha R. Flesher, ${ }^{1,2}$ Eileen A. Hebets, ${ }^{3}$ \\ and Verner P. Bingman ${ }^{1,2}$

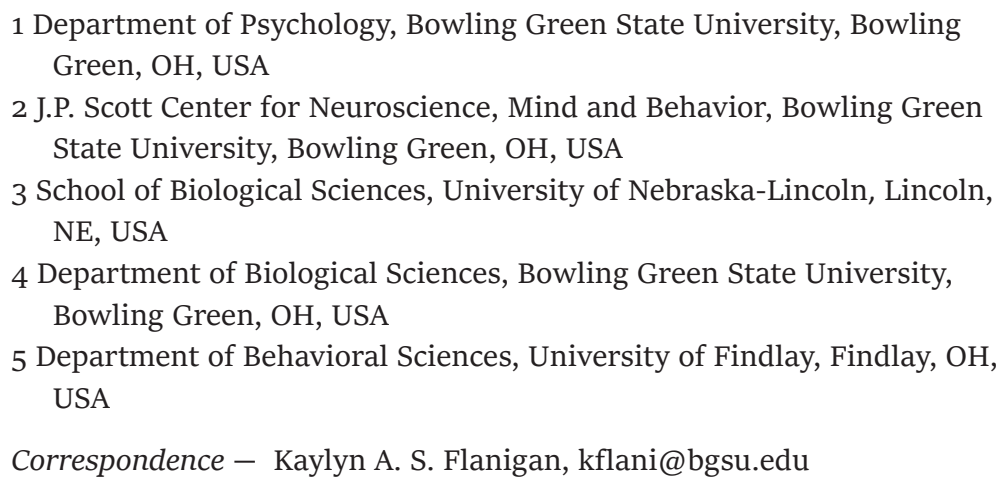

\begin{abstract}
Amblypygids, or whip spiders, are nocturnally active arachnids which live in structurally complex environments. Whip spiders are excellent navigators that can re-locate a home refuge without relying on visual input. Therefore, an open question is whether visual input can control any aspect of whip spider spatial behavior. In the current study, Phrynus marginemaculatus were trained to locate an escape refuge by discriminating between differently oriented black and white stripes placed either on the walls of a testing arena (frontal discrimination) or on the ceiling of the
\end{abstract}

Published in Journal of Comparative Physiology A 207 (2021), pp 729-737.

doi:10.1007/soo359-021-01509-y

Copyright (C) 2021 Flanigan et al. under exclusive license to Springer-Verlag GmbH

Germany, part of Springer Nature 2021. Used by permission.

Submitted 17 April 2021; revised 1 September 2021; accepted 9 September 2021; published 30 September 2021. 
same testing arena (overhead discrimination). Regardless of the placement of the visual stimuli, the whip spiders were successful in learning the location of the escape refuge. In a follow-up study of the overhead discrimination, occluding the median eyes was found to disrupt the ability of the whip spiders to locate the shelter. The data support the conclusion that whip spiders can rely on vision to learn and recognize an escape shelter. We suggest that visual inputs to the brain's mushroom bodies enable this ability.

Keywords: Amblypygi, Navigation, Occlusion, Spatial learning, Vision

\section{Introduction}

Visual guidance of behavior in terrestrial arthropods has been studied extensively in species that live and forage in structurally simple habitats (reviewed by Cheng 2012). For example, the desert ant, Cataglyphis fortis, uses atmospheric polarized light as a compass to guide their return journey to a nest (Wehner 2003; Collett 2012). Additionally, visual landmark cues along a repeated, familiar route can be used to locate a goal (e.g., a nest or food source) (Fukushi and Wehner 2004; Cheng et al. 2009; Collett 2012). The Australian desert ant, Melophorus bagoti, and the bull ant, Myrmecia pyriformis, have also been shown to use vision of the skyline panorama to guide navigation (Graham and Cheng 2009; Reid et al. 2011). As examples of visually guided spatial behavior in non-hymenopterans, the fiddler crab, Uca perplexa, also uses visual landmarks to guide navigation back to a nest after foraging (Murakami et al. 2017), and dung beetles have been shown to use celestial cues at night to push dung balls to their nests (Dacke et al. 2021).

Visually guided, goal-directed behavior is also common in arachnids. For example, the funnel weaving spider, Agelena labyrinthica, has been shown to use visual cues to guide path integration on its web (Gorner 1962; Gorner and Claas 1985; Moller and Gorner 1994). In non-web-building spiders like the wandering spider, Leucorchestris arenicola, males have been shown to use visual cues for navigation at night (Norgaard et al. 2008). L. arenicola may amplify its light-gathering capacity as it starts and stops along its journey, facilitating the detection of features like the desert skyline (Norgaard et al. 2006). The ground spider, Drassodes cupreus, uses polarized light, detected by its secondary eyes, as a compass for returning to a previously established 
refuge (Dacke et al. 1999). Using path integration, the wolf spider, $L y$ cosa tarentula, navigates home by relying on sun or polarized light cues processed by the anterior lateral and median eyes (Ortega-Escobar and Munoz-Cuevas 1999; Ortega-Escobar 2011).

Whip spiders are a group of arachnids (Order Amblypygi) that display robust navigational abilities (see reviews by Gaffin and Curry 2020; Ortega-Escobar 2020). Whip spiders are nocturnal predators that faithfully occupy diurnal refuges on tree crevices, cliff banks and caves in tropical and subtropical habitats (Weygoldt 2000; Santer and Hebets 2011; Corey and Hebets 2017). In at least epigean species of whip spiders, activity-including exiting and re-entering a refugeis highly correlated with the environmental light-dark cycles, where animals exit their refuge within the first hour of the dark phase and typically search for, and return to, their refuge within the last few hours before first light of dawn (Weygoldt 2000). Sensory guidance of their navigational behavior (Santer and Hebets 2009; Hebets et al. 2014b; Bingman et al. 2017; Casto et al. 2019, 2020; Wiegmann et al. 2019) seems to be overwhelmingly dependent on their antenniform legs (i.e., the thin, elongated front pair of nonambulatory legs), which have evolved to detect chemical and mechanical stimuli (Foelix et al. 1975, 2002; Beck et al. 1977; Igelmund 1987; Hebets and Chapman 2000; Foelix and Hebets 2001; Spence and Hebets 2007). Vision does not appear necessary for whip spiders to navigate between their home shelter and hunting sites (Beck and Gorke 1974; Hebets et al. 2014b; Bingman et al. 2017; Graving et al. 2017). However, most species of whip spiders have eight simple eyes, one pair of median eyes and a bilateral set of three eye pairs positioned antero-laterally on the dorsal surface of the prosoma (Weygoldt 2000; Fig. 1a), raising the question of whether any aspect of their navigational behavior could be guided by vision. The development of whip spider median and lateral eyes is like that found in other arthropods (Paulus 1979; Weygoldt 2000; Lehmann and Melzer 2018) and shares similar developmental gene control (Gainett et al. 2020). As such, the cellular organization of the median eyes, which develop from an invagination during embryogenesis, is more densely packed with retinula cells compared to the lateral eyes, and the closed rhabdoms are everted with respect to incoming light (Weygoldt 2000). By contrast, the lateral eyes, as a group, have a wide field of view and low resolution that may serve to detect 

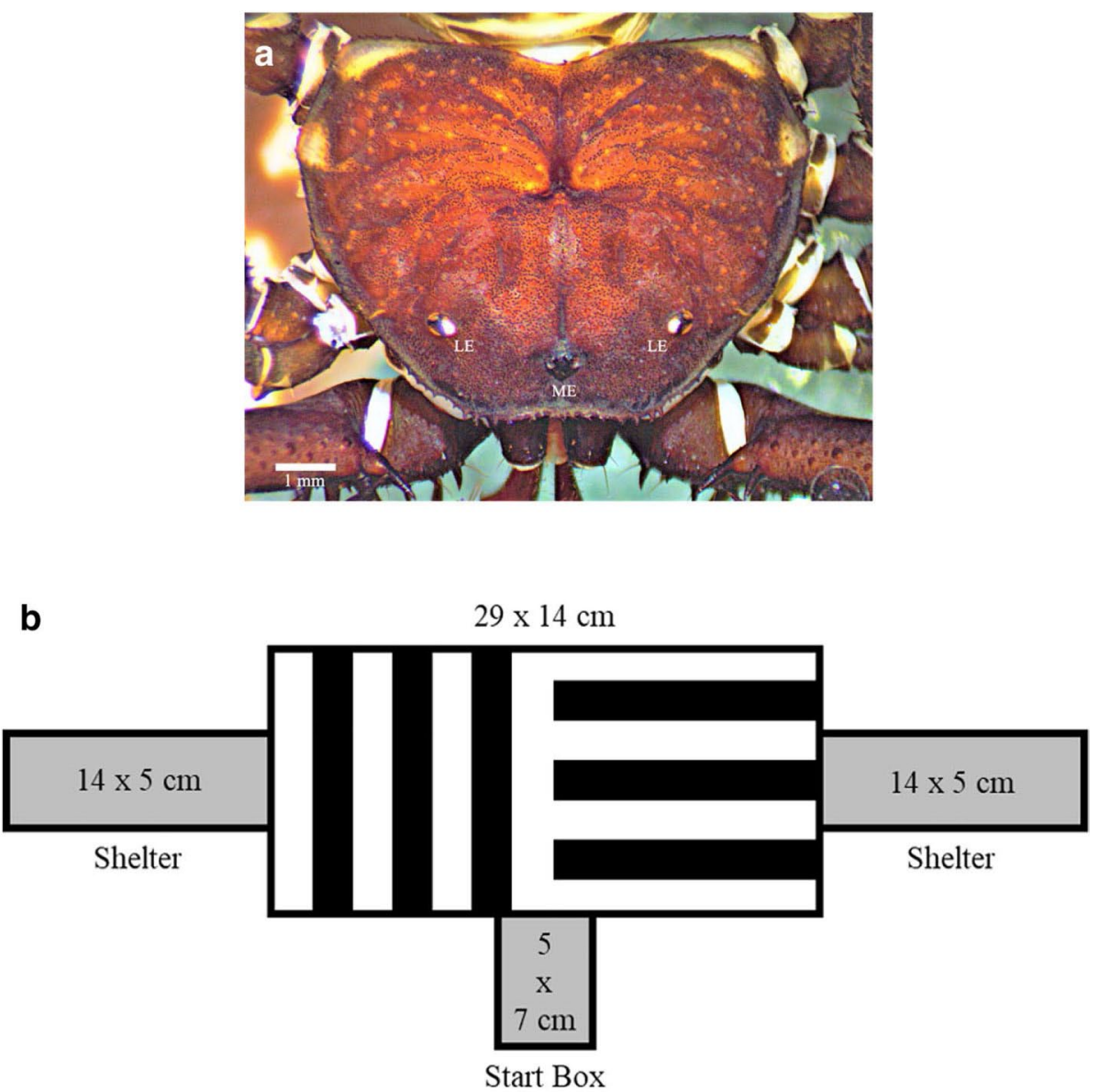

Fig. 1 a) Whip spider prosoma with lateral eye pairs (LE) and median eyes (ME). b) Schematic representation of the training and testing arena used in the experiments. Visual cues are presented as they would be on an overhead trial. Subjects are acclimated in the "start box" before and between the training and test trials of their daily sessions. On training trials, the shelter entrance is open on the CS + side (the CS + visual pattern was balanced across subjects and the position of the CS + was pseudorandomly changed across trials). On test trials, neither shelter entrance was open

variation in ambient light levels (Weygoldt 2000). The lateral eyes of Phrynus marginemaculatus have an irregular rhabdomeral organization and a tapetum that appears to be canoe-shaped (Geberhardt 1983 as cited in Weygoldt 2000). This suggests images are not well focused on the lateral eye retinae (Land 1985). Additionally, recent neuroanatomical evidence revealed that the large mushroom body calyces of whip spiders have neural inputs from associated visual neuropils (Sinakevitch et al. 2021), suggesting that vision plays an important 
role in learning and memory processes including those that may support navigation (Srinivasan 2010; Strausfeld 2012; Devaud et al. 2015; Wiegmann et al. 2016).

The current study set out to investigate the possible role of vision in guiding spatial learning in $P$. marginemaculatus. In the first experiment, animals were trained on a visual discrimination task in which one visual stimulus was associated with an escape refuge (i.e., an open shelter) while another visual stimulus was associated with no escape opportunity (i.e., a closed shelter). Furthermore, the visual stimuli were presented either on the walls (frontal) or on the ceiling (overhead) of the enclosure to assess potential differences in the use of cues based on their location in the visual field. The data revealed above chance accuracy in locating the shelter using both frontal and overhead visual cues. A second experiment investigated the role of the median eyes in visual discrimination. When visual inputs to the median eyes were blocked, subjects were no longer able to locate the shelter. Thus, the current study demonstrates that $P$. marginemaculatus can learn to discriminate the spatial position of an escape refuge using visual cues, and that the median eyes are important for that visual discrimination.

\section{Methods}

\section{Visual shelter recognition}

\section{Subjects}

Ten Phrynus marginemaculatus, collected from the Florida Keys (USFWS Permit Number FFO4RFKD-2015-06), were used for this experiment. Subjects were housed alone in plastic deli containers (diameter $17.1 \mathrm{~cm}$, height $10.8 \mathrm{~cm}$ ) containing coconut fiber substrate and a portion of cardboard egg carton, which served as a shelter. Feeding occurred two to three times weekly and the inside of containers was misted daily to increase humidity and provide access to water. Ambient room humidity ranged from 20 to $60 \%$ and temperature ranged from 21 to $26^{\circ} \mathrm{C}$. The room was lit by overhead, broad-spectrum fluorescent lights (400-700 nm) on a 12:12 light:dark cycle (19:00-7:00, dark). 


\section{Experimental apparatus}

Visual discrimination training and testing occurred in a white opaque acrylic arena $(29 \mathrm{~cm} \times 14 \mathrm{~cm}, \mathrm{~L} \times \mathrm{W})$ with floor-level holes $(3 \mathrm{~cm} \times$ $1 \mathrm{~cm}, \mathrm{~L} \times \mathrm{H}$ ) centered on each of the shorter walls and on one long wall (Fig. 1b). A clear, acrylic ceiling covered the arena. The long axis of the arena was divided into equal halves with the boundary identified by a line marked on the floor. Two 6o-W spiral CFL light bulbs (90o lumens) were clamped to each end wall pointing downward 28 $\mathrm{cm}$ above the arena floor. Whip spiders are nocturnal animals, and the lights served to motivate subjects to seek refuge in a dark shelter. The rewarding dark shelters, made of black acrylic $(14 \mathrm{~cm} \times 5 \mathrm{~cm}, \mathrm{~L}$ $\times \mathrm{W}$ ), were placed against the floor-level holes on both short walls. The floor-level hole in the middle of one long wall was used to release subjects into the arena.

Visual stimuli

Visual cues consisted of alternating, black and white striped panels that could be placed overhead on the arena ceiling or on the walls of the short ends of the arena. The width of each stripe was $2 \mathrm{~cm}$. Initially, half the subjects were tested with the striped panels on the walls (frontal; the orientation of the stripes differed by 90 degrees for each wall), and half the subjects were tested with the striped panels on the ceiling (overhead; the orientation of the stripes on each half of the arena ceiling also differed by $90^{\circ}$ ). For each type of discrimination task (frontal or overhead), subjects were trained for five sessions (see Discrimination training/testing). After completing the sessions of one discrimination type, subjects were trained on the other. For the frontal discrimination, half the subjects had the escape shelter $(\mathrm{CS}+)$ associated with vertical stripes and half the subjects with horizontal stripes; the blocked shelter (CS-) was associated with alternate striped pattern. For the overhead discrimination, half the subjects had the escape shelter (CS +) associated with stripes that ran parallel to the long axis of the arena and half the subjects with stripes that ran perpendicular to the long axis of the arena; the blocked shelter (CS-) was associated with the alternate striped pattern. Across the trials of a session, the position of the CS + varied pseudo-randomly such that 
the CS + could not be on the same side of the arena for more than two trials in a row. No differences were found in discrimination ability based on whether a subject was trained first on the overhead or frontal stimuli. Therefore, the data from all 10 subjects trained on the frontal discrimination were pooled, as were the data from the overhead discrimination.

\section{Discrimination training/testing}

For each of the five training sessions (one session/day), subjects were given seven trials. Trials 2-6 were "training trials" with the CS + shelter entrance open and the CS- shelter entrance closed. The first and seventh trials of each session are referred to as beginning session test trials and end session test trials, respectively. Prior to training or test trials, subjects were gently placed in an enclosed black acrylic "start box" positioned in front of the arena entrance on the long axis for a five-minute acclimation period. Following acclimation, a piece of black acrylic formerly blocking the entrance into the arena was removed. Subjects were gently coerced into the arena with a blunt dissection probe and the entrance into the arena blocked once again.

During training trials, subjects were given up to fifteen minutes to wander the arena and enter the open shelter $(\mathrm{CS}+)$. If, in the rare occurrence, an animal remained in the arena after fifteen minutes, it was gently coerced into the open shelter. Once subjects had entered the CS + shelter, they were blocked from re-entering the arena and left undisturbed for five minutes. After five minutes, subjects - still inside the shelter - were moved to the start entrance and the next trial began (i.e., the escape shelter of the previous trial served as the start shelter for the next trial). Importantly, for each trial, the "open" escape shelter was one that was not used previously and therefore could not have contained any residual odor cues that could have enabled discrimination (see Casto et al. 2019).

During beginning and end session test trials, CS + and CS- shelter entrances were closed. Closed entrances of both CS + and CS- allowed for a measure of cue preference in contrast to an immediate escape response due to the aversive light stimulus. In these tests, the time a subject spent in each half of the arena during the fifteen-minute trial was recorded. 


\section{Data analysis}

For test trials, an association index $(\theta)$ was computed by dividing the time (in seconds) spent in the half of the arena associated with CS + by the total time of the test, where $0 \leq \theta \leq 1$. Association indices close to $\theta=1$ indicate that subjects learned to associate the CS + visual cues with a shelter, while indices close to $\theta=0.5$ indicate that subjects did not learn the association. Separate analyses were carried out for beginning and end session test trial data. The reasoning was that beginning session test trial data reflected longer-term memory carried over from training on previous days, whereas end session test trial data reflected a blend of across and within session memory. A 2 (cue location: frontal, overhead) $\times 4$ (daily session: day 2 , day 3 , day 4 , day 5 ) repeated measures ANOVA was used to investigate possible changes in beginning session test trial association index scores across session days and a possible effect of cue location on association index scores. Note that only four session days, beginning with day 2, were analyzed for beginning session test trials because no training occurred before the first beginning session test trial on training day one. Similarly, a 2 (cue location: frontal, overhead) $\times 5$ (daily session: day 1 , day 2 , day 3 , day 4 , day 5 ) repeated measures ANOVA was used to analyze end session test trial data.

Additionally, four one-sample $t$ tests were used to determine whether subjects could discriminate the cue associated with the open shelter above chance (i.e., association index score of $\theta>0.5$ ) on the last day of training sessions (day 5; frontal beginning session test, frontal end session test, overhead beginning session test, overhead end session test). Finally, to further probe whether the position of the discriminative cues influenced the recorded association indices, two (one for the beginning session test and one for end session test data) paired-samples $t$ tests were used to compare frontal association index scores against overhead association index scores for both test trials. All analyses were performed using SPSS Statistics for Windows, Version 25.0 and the criterion for significance was $p<0.05$.

Importance of the median eyes

While the main goal of the current study was to investigate learned visual-shelter recognition in whip spiders, we followed the visual 
discrimination experiment with an experiment in which the median eyes were occluded to test the possible importance of the median eyes in supporting the observed visual recognition learning.

\section{Subjects}

Four of the ten subjects from the visual discrimination experiment were chosen randomly and used in the median eye occlusion experiment. A range of 38-62 days elapsed between the last session of training on visual discrimination and the first session of median eye occlusion.

\section{Pre-occlusion discrimination re-training}

The data from the visual discrimination experiment suggested that the overhead discrimination of the subjects may have been easier to learn (see Results). Therefore, only overhead cues were used for this experiment. Training sessions were similar to those used in the first experiment, with two exceptions. First, for both training and testing, trials lasted for up to ten minutes instead of fifteen minutes. Second, subjects progressed to the occlusion phase of this experiment only after either an average association index of 0.65 or greater was achieved for three out of four sessions for both beginning and end session test trials, or after a subject had been trained over a total of eight sessions. We employed a criterion here to ensure that the subjects were at a performance level that would enable a detection of a possible decline in performance following occlusion.

Median eye occlusion

Within two days of reaching a criterion, each subject was gently held in place by the carapace and, using the end of a blunt dissection probe, had the median eyes covered with black nail polish (Sally Hansen Insta-Dry, black). It has been demonstrated that this method of eye occlusion in whip spiders is not harmful and does not disrupt navigation in the field (Bingman et al. 2017). Animals were then placed back into their home shelter. One day after eye occlusion, subjects began training again on the previously learned discrimination. Training continued 
for eight sessions. All other procedures were identical to the original visual discrimination training.

\section{Data analysis}

Association index scores $(\theta)$ were calculated as in the visual discrimination experiment. We were specifically interested in comparing the terminal performance of each subject on the pre- and post-occlusion training. Therefore, two paired-samples $t$ tests were used to compare each subject's average association index scores across the last three pre-occlusion sessions to the average association index scores across the last three sessions' post-occlusion tests for the beginning session test trial and the end session test trial data separately. Additionally, two one-sample $t$ tests were used to compare the mean association indices of the last three pre-occlusion tests and the last three tests postocclusion for both beginning and end session test trial data against random chance (0.5). All analyses were performed using SPSS Statistics for Windows, Version 25.0 and the criterion for significance was $p<0.05$.

\section{Results}

\section{Visual discrimination shelter recognition}

A two-factor repeated measures ANOVA was used to investigate possible changes in beginning session test trial association index scores across training days and for a possible effect of cue location. No main effect of training day $\left(F_{3,27}=1.36, p=0.28\right)$, or cue location $\left(F_{1,9}=\right.$ 2.32, $p=0.16$ ) was found. Additionally, no significant interaction between training day $\mathrm{x}$ cue location was found $\left(F_{3,27}=0.93, p=0.44\right)$. A two-factor repeated measures ANOVA was used to investigate the end session test trial data, results of which revealed no main effect of training day $\left(F_{4,36}=0.60, p=0.66\right)$, cue location $\left(F_{1,9}=2.70, p=0.14\right)$, nor training day $\times$ cue location interaction $\left(F_{4,36}=1.22, p=0.32\right)$.

The lack of a training day effect for test trials suggests that learning to associate the correct visual stimulus with the open shelter may have proceeded quickly with little additional learning taking place in 


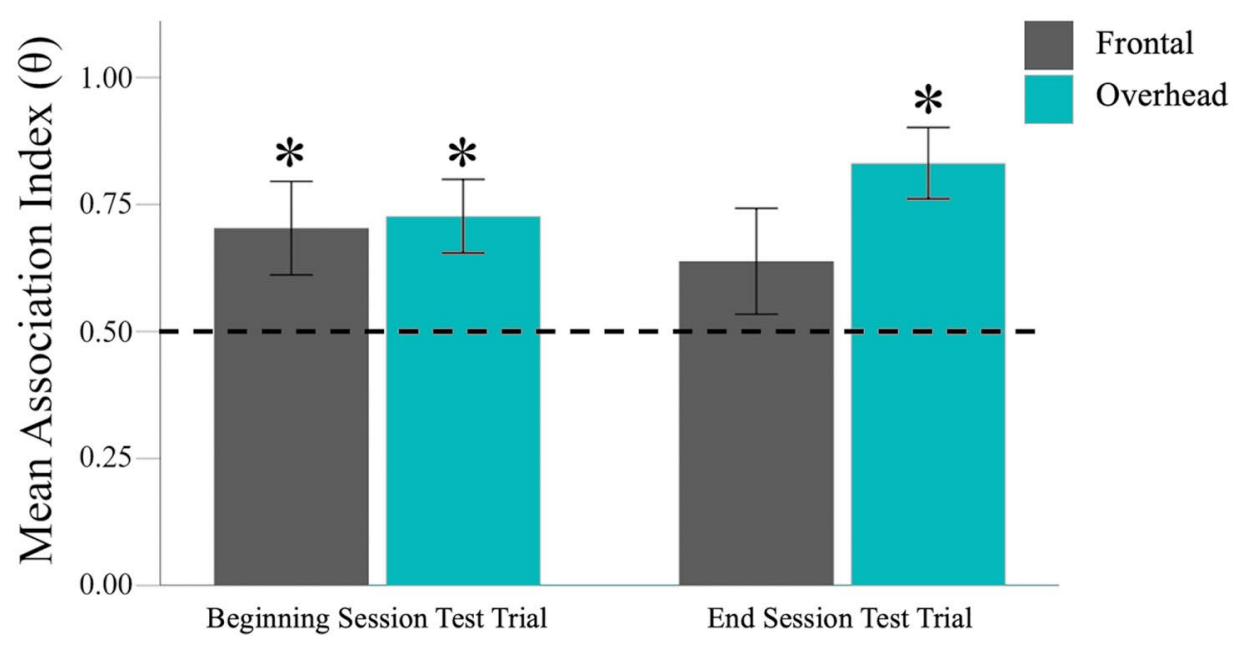

Fig. 2 Mean $( \pm S E)$ association index scores $(\theta)$ for beginning session test trial and end session test trial data, separated by cue position (Frontal: dark gray; Overhead: light gray). Dashed line indicates chance performance (i.e., a 0.5 association index, indicating equal time spent on each side of the arena). $\left({ }^{*}\right)$ indicates an association index significantly greater than chance $(\mathrm{p}<0.05)$

the latter sessions, a result partially confirmed by follow-up one-sample $t$ tests. Looking at the data from session five, the last day of training, the mean association index of the beginning session test was significantly greater than chance when the visual stimuli were placed frontally $\left(M=0.70, S E=0.09, t_{9}=2.21, p<0.03\right)$, or overhead $(M=$ $0.73, S E=0.07, t_{9}=3.13, p<0.01 ;$ Fig. 2). For end session test trials, the whip spiders again performed better than chance when the visual stimulus was placed overhead $\left(M=0.83, S E=0.07, t_{9}=4.72, p\right.$ $<$ o.01). However, although showing a preference for the CS + visual stimulus, the mean association index for the frontal end session trial tests did not reach significance $\left(M=0.64, S E=0.10, t_{9}=1.33, p=\right.$ o.11; Fig. 2). Together, the data strongly support the hypothesis that, by the end of training, the whip spiders were able to learn the location of the escape shelter by relying on the associated visual stimulus.

To further assess possible cue location-related differences in discrimination performance at the end of training (day 5), a paired-samples $t$ test was used to compare frontal association index scores to the overhead association index scores. The comparison revealed no statistical difference, but a slight graphical trend, in an ability to use 


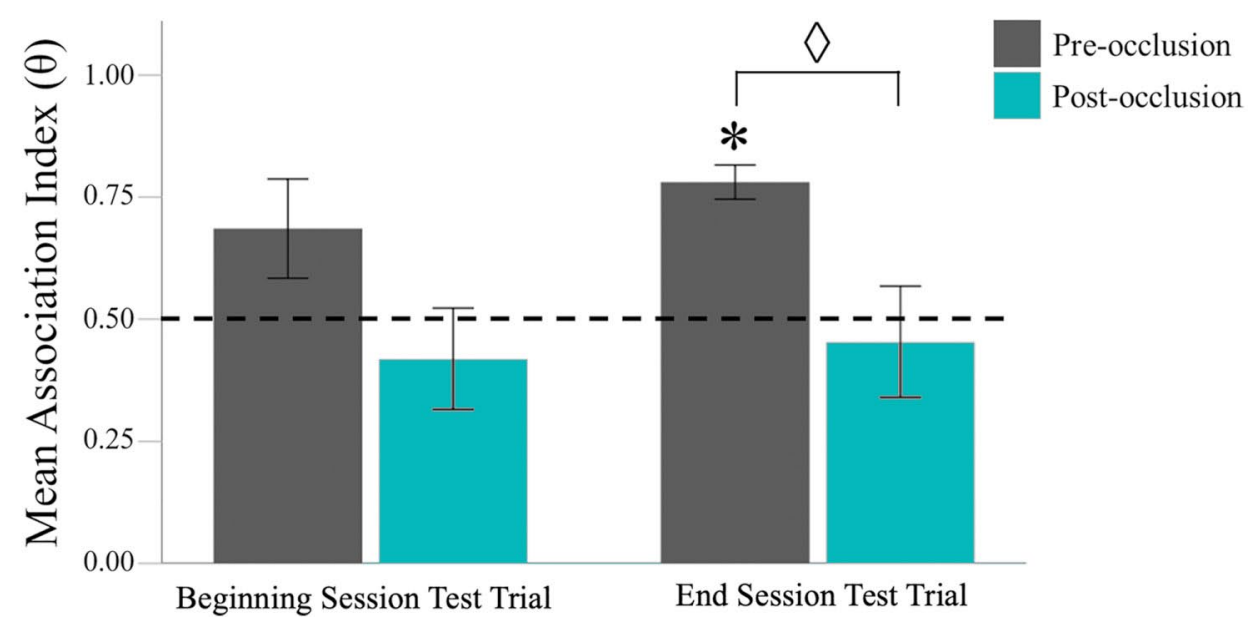

Fig. 3 Mean ( \pm SE) association index scores $(\theta)$ for beginning session test trial and end session test trial data, separated by pre-occlusion (dark gray) and post-occlusion (light gray) of the median eyes. Note that the subjects were only trained on the overhead discrimination. Dashed line indicates chance performance (i.e., a 0.5 association index, indicating equal time spent on each side of the arena). $\left(^{*}\right)$ indicates an association index significantly greater than chance, while $(\diamond)$ indicates a significant difference between pre- and post-occlusion scores $(p<0.05)$

either cue location to approach the open shelter in beginning session test trials $\left(t_{9}=0.20, p=0.85\right)$ and end session test trials $\left(t_{9}=1.62\right.$, $p=0.14$, Fig. 2).

\section{Median eye occlusion}

In our second experiment, we investigated whether the median eyes, the eyes most likely capable of supporting high-resolution image formation compared to the morphology of the lateral eyes (Weygoldt 2000; Graving et al. In prep.), are necessary for the observed visualspatial learning. We chose to do so for the overhead discrimination, which appeared to be the easier of the two tasks (Fig. 2). To address this, paired-samples $t$ tests were used to compare the mean association index scores across the last three pre-occlusion sessions to the mean association index scores across the last three post-occlusion sessions for both beginning session and end session test trial data. Inspection of Fig. 3 suggests that post-occlusion, the performance of the whip spiders dropped dramatically. The impression 
was statistically confirmed for the end session test trial: preocclusion $(M=0.78, S E=0.04)$ compared to post-occlusion $(M=0.45$, $S E=0.11, t_{3}=3.57, p<0.04$; Fig. 3). Although a similar post-occlusion drop in performance was observed for the beginning session test trial data, that contrast was not significantly different: pre-occlusion $(M=0.69, S E=0.10)$ compared to post-occlusion $(M=0.42$, $S E=0.10, t_{3}=1.83, p=0.17$; Fig. 3).

Additionally, one-sample $t$ tests were used to compare the mean association index over the last three pre-occlusion and post-occlusion sessions against chance (0.5) for both beginning and end session test trials. Consistent with the hypothesis that the median eyes are necessary for the observed visual discrimination, spiders performed significantly greater than chance on pre-occlusion end session test trials $\left(t_{3}=8.00, p<0.01, M=0.78, S E=0.4\right)$. The pre-occlusion beginning session test trial means, despite appearing above chance, did not reach significance $\left(t_{3}=1.83, p=0.17, M=0.69, S E=0.10\right)$. By contrast, the mean association index scores of post-occlusion beginning session test trials $\left(t_{3}=0.78, p=0.49, M=0.42, S E=0.10\right)$ and postocclusion end session test trials $\left(t_{3}=0.41, p=0.71, M=0.45, S E=\right.$ 0.11; Fig. 3) did not suggest any difference from chance. Although the data are taken from only four subjects, they nonetheless offer strong evidence that the median eyes are necessary for the observed visualspatial learning.

\section{Discussion}

The results of this study indicate that whip spiders possess the capability to use visual cues to locate a home refuge. Subjects trained to find an open shelter using visual cues generally performed significantly better than chance during test trials across five days. This finding is of particular interest as previous research showed that vision is not required for whip spider navigation (Bingman et al. 2017), although its potential use was suggested in another study (Hebets et al. 2014a). It is important to note that the current study only indicates the potential importance of vision for the terminal stage of whip spider nocturnal navigation, namely the near-distance localization of a diurnal shelter. 
The performance of subjects in beginning session tests in this study demonstrates a moderately long-term characteristic of the acquired visual-spatial memories, as the animals showed a preference for the visual stimuli associated with the home shelter $24 \mathrm{~h}$ after the previous training sessions. Formation of such memories would be of evolutionary advantage to organisms like whip spiders that return to, and are faithful to, one refuge for long periods of time. Similar memoryguided navigation has been demonstrated in whip spiders trained to associate the location of a shelter with an olfactory cue. In the olfactory study, subjects reliably located home shelters using retained olfactory cue memories during trials that occurred 14 days after the last training (Wiegmann et al. 2019).

Visual-based navigation has been studied in many insects which are sensitive to visual characteristics, such as object color, size, symmetry, and pattern (see reviews Collett and Collett 2002; Mandal 2018). In addition to the many insects that may use visual cues to navigate, many arachnid species have been demonstrated to do the same. The silk nest-building jumping spider, Phidippus clarus, which expresses fidelity to a refuge after an outbound journey, for instance, uses visual cues to recognize the area around its nest (Hoefler and Jakob 2006). Cupiennius salei, a South American wandering spider, has similar navigational challenges as whip spiders (e.g., nocturnal activity in lowlight environments, refuge seeking through complex substrates). $C$. salei has been shown to discriminate between and move toward visual cues (Schmid, 1998), but its use of visual cues for the context of navigation is still largely unknown (see review by Gaffin and Curry 2020).

Previous research also supports the hypothesis that insects and spiders can recall visual memories. Specifically, wood ant subjects take "snapshots" of landmark cues and use them to navigate to their goal location (Durier et al. 2003). Visual memories of prey size were also shown in three different species of spiders (Rodriguez and Gamboa 2000). Given the extensive use of visual cues in arthropods, which includes some nocturnal arachnids, it is not surprising that whip spiders have sufficient visual acuity to navigate to a home refuge.

Our second experiment was intended to offer an assessment of the possible importance of the median eyes in supporting the visual recognition of a home refuge. Schmid (1998) found that when the primary eyes of $C$. salei were occluded, its ability to discriminate between 
visual targets was diminished. In our second experiment, we occluded the median eyes of our subjects because the structure of the median eyes appears better suited for image formation than the lateral eyes due to the closed rhabdomeral organization (Paulus 1979; Weygoldt 2000; Lehmann and Melzer 2018; Graving et al. In prep). Following median eye occlusion, visual discriminative ability for the shelter location decreased to chance level. This result suggests that the median eyes are necessary for the visual discrimination task used in the current study. However, this observation does not exclude the potential importance of the lateral eyes for the same discrimination task, which still needs to be investigated.

The successful visual-spatial learning observed in the current paper raises the question of underlying neural mechanisms. In arthropods, the mushroom bodies are often cited as the center of cognition supporting learning and memory (Menzel et al. 2006; Strausfeld et al. 2009). In whip spiders, these brain centers are exceptionally large (Strausfeld et al. 1998), and we hypothesized that the mushroom bodies support learning and memory in the service of navigation, including multisensory configural learning (Wiegmann et al. 2016; Flanigan et al. 2021). It is therefore notable that a recent paper described visual inputs to the mushroom bodies of whip spiders (Sinakevitch et al. 2021). Curious, however, is that the major visual input to the mushroom bodies was observed to come from the lateral eye medulla, whose input originates with the optically simpler lateral eyes, which have fewer retinula cells, an irregular, open rhabdomeral organization, and a tapetum shape that suggests poor image forming ability (Gebhardt 1983 as cited in Weygoldt 2000). A study by Lehmann and Melzer (2018) revealed that the median eyes have two neuropils, one of which possesses a few retinula cell fibers which leave the second neuropil and terminate on the second lateral eye neuropil. The authors hypothesize that termination of a median and lateral eye tract in a similar region may represent "pre-integration" of visual information. In contrast to Sinakevitch et al. (2021), they found no connection between the neuropil and the mushroom bodies. Definitive evidence of a visual neuropil to mushroom body projection could help explain the visual learning capabilities in whip spiders.

In conclusion, the visual capabilities of whip spiders in the context of navigation have been overlooked because of the notably necessary 
sensory inputs from the antenniform legs (Bingman et al. 2017). However, the current study provides evidence that vision can be used as another tool in the whip spider sensory-modality toolbox to guide navigation, and home refuge recognition in particular. Future research should include tests of more complex pattern recognition as well as tests of the possible contributions from the whip spider lateral eyes. Additionally, investigating potential visual processing by the mushroom bodies could prove invaluable for understanding the underlying neurobiology of whip spider learning and spatial memory.

\section{Supplementary Tables $1 \& 2$ follow the References.}

Author contributions Conceptualization and Methodology: DDW, EAH, VPB; Investigation: NRF; Data Curation: NRF, VJC, VPB; Writing: KASF, PC, VJC, VPB; Funding Acquisition: DDW, VPB.

Funding We are grateful for financial support from the National Geographic Society and the National Science Foundation (IOS 1457304).

Data availability Data available in supplementary tables.

Code availability Not applicable.

Conflicts of interest The authors declare no competing or financial interests.

Animal care All experimental procedures followed the Animal Care and Use guidelines set forth by the National Institute of Health.

\section{References}

Beck L, Gorke K (1974) Tagesperiodik, Revierverhalten und Beutefang der Geisselspinne Admetus pumilio C. L Koch Im Freiland Z Tierpsychol 35:173-186

Beck L, Foelix R, Godeke E, Kaiser R (1977) Morphologie, Larvalentwicklung und Haarsensillen des Tastbeinpaares der Geiselspinne Heterophrynus longicornis Butler (Arach., Amblypygi). Zoomorphol 88:259-276

Bingman VP, Graving JM, Hebets EA, Wiegmann DD (2017) Importance of the antenniform legs, but not vision, for homing by the neotropical whip spider 
Paraphrynus laevifrons. J Exp Biol 220:885-89o. https://doi.org/10.1242/ jeb.149823

Casto P, Gosser J, Wiegmann DD, Hebets EA, Bingman VP (2019) Self-derived chemical cues support home refuge recognition in the whip spider Phrynus marginemaculatus (Amblypygi: Phrynidae). J Arachnol 47(2):290-292. https:// doi.org/10.1636/joa-s-18-067

Casto P, Wiegmann DD, Coppola VJ, Nardi D, Hebets EA, Bingman VP (2020) Vertical-surface navigation in the Neotropical whip spider Paraphrynus laevifrons (Arachnida: Amblypygi). Anim Cogn 23(6):1205-1213. https://doi. org/10.1007/s10071-020-01420-O

Cheng K (2012) Arthropod navigation: ants, bees, crabs, spiders finding their way. In: Zentall TR, Wasserman EA (eds) The Oxford Handbook of Comparative Cognition. Oxford University Press, New York, pp 347-365

Cheng K, Narendra A, Sommer S, Wehner R (2009) Traveling in clutter: navigation in the central Australian desert ant Melophorus bagoti. Behav Process 8o(3):261-268. https://doi.org/10.1016/j.beproc.2008.10.015

Collett M (2012) How navigational guidance systems are combined in a desert ant. Curr Biol 22(10):927-932. https://doi.org/10.1016/j.cub.2012.03.049

Collett TS, Collett M (2002) Memory use in insect visual navigation. Nat Rev Neurosci 3(7):542-552. https://doi.org/10.1038/nrn872

Corey TB, Hebets EA (2017) Microhabitat use in the amblypygid Paraphrynus laevifrons. J Arachnol 45(2):223-230. https://doi.org/10.1636/JoA-S-16-055.1

Dacke M, Baird E, el Jundi B, Warrant EJ, Byrne M (2021) How dung beetles steer straight. Annu Rev Entomol 66:243-256. https://doi.org/10.1146/ annurev-ento-042020-102149

Dacke, M, Nilsson, DE, Warrant, E (1999) Built-in polarizers form part of a compass organ in spiders. Nature 401: 470-473. https://doi.org/10.1038/46773

Devaud JM, Papouin T, Carcaud J, Sandoz JC, Grunewald B, Giurfa M (2015) Neural substrate for higher-order learning in an insect: mushroom bodies are necessary for configural discriminations. PNAS 112(43):E5854-E5862. https:// doi.org/10.1073/pnas.1508422112

Durier V, Graham P, Collett TS (2003) Snapshot memories and landmark guidance in wood ants. Curr Biol 13(18):1614-1618. https://doi.org/10.1016/j. cub.2003.08.024

Flanigan KAS, Wiegmann DD, Hebets EA, Bingman VP (2021) Multisensory integration supports configural learning of a home refuge in the whip spider Phrynus marginemaculatus. J Exp Biol 224(Pt 3): jeb238444. https://doi. org/10.1242/jeb.238444

Foelix RF, Hebets EA (2001) Sensory biology of whip spiders (Arachnida, Amblypygi). Andrias 15:129-140

Foelix RF, Chu-Wang IW, Beck L (1975) Fine structure of tarsal sensory organs in the whip spider Admetus pumilio (Amblypygi, Arachnida). Tissue Cell 7(2):331346. https://doi.org/10.1016/0040-8166(75)90009-9 
Foelix R, Troyer D, Igelmund P (2002) Peripheral synapses and giant neurons in whip spiders. Microsc Res 58(4):272-282. https://doi.org/10.1002/jemt.10136

Fukushi T, Wehner R (2004) Navigation in wood ants Formica japonica: context dependent use of landmarks. J Exp Biol 207:3431- 3439. https://doi. org/10.1242/jeb.01159

Gaffin DD, Curry CM (2020) Arachnid navigation - a review of classic and emerging models. J Arachnol 48(1):1-25. https://doi. org/10.1636/0161-8202-48.1.1

Gainett G, Ballesteros JA, Kanzler CR, Zehms JT, Zern JM, Aharon S, Gavish-Regev E, Sharma PP (2020) Systemic paralogy and function of retinal determination network homologs in arachnids. BMC Genom 21:811. https://doi.org/10.1186/ s12864-020-07149-X

Gebhardt I (1983) Vergleichend-morphologische und histologische Untersuchungen an Augen von Spinnentieren unter besonderer Berucksichtigung der Pseudoscorpiones. Thesis, University of Freiburg, Freiburg im Breisgau, Uropygi und Amblypygi Gorner P (1962) Die Orientierung der Trichterspinne nach polarisiertem Licht. Z verglPhysiol 45:307-314

Gorner P, Claas B (1985) Homing behavior and orientation in the funnelweb spider, Agelena labyrinthica Clerck. In: FG Barth (ed) Neurobiology of Arachnids Springer, Berlin, Heildelberg, pp 275-297. https://doi. org/10.1007/978-3-642-70348-5 14

Graham P, Cheng K (2009) Which portion of the natural panorama is used for view-based navigation in the Australian desert ant? J Comp Phys A 195(7):681689. https://doi.org/10.1007/s00359-009-0443-6

Graving JM, Bingman VP, Hebets EA, Wiegmann DD (2017) Development of site fidelity in the nocturnal amblypygid Phrynus Marginemaculatus. J Comp Phys A 203(5):313-328. https://doi.org/10.1007/s00359-017-1169-5

Hebets EA, Chapman RF (2000) Electrophysiological studies of olfaction in the whip spider Phrynus parvulus (Arachnida, Amblypygi). J Insect Phys 46(11):1441-1448. https://doi.org/10.1016/So022-1910(00)00068-8

Hebets EA, Aceves-Aparicio A, Aguilar-Arguello S, Bingman VP, Escalante I, Gering EJ, Nelsen DR, Rivera J, Sanchez-Ruiz JA, Segura-Hernandez L, Settepani V, Wiegmann DD, Stafstrom JA (2014a) Multimodal sensory reliance in the nocturnal homing of the amblypygid Phrynus pseudoparvulus (Class Arachnida, Order Amblypygi). Behav Process 108:123-130. https://doi.org/10.1016/j. beproc.2014.09.014

Hebets EA, Gering EJ, Bingman VP, Wiegmann DD (2014b) Nocturnal homing in the tropical amblypygid Phrynus pseudoparvulus (Class Arachnida, Order Amblypygi). Anim Cogn 17(4):1013- 1018. https://doi.org/10.1007/ s10071-013-0718-8

Hoefler CD, Jakob EM (2006) Jumping spiders in space: movement patterns, nest site fidelity and the use of beacons. Anim Behav 71:109-116. https://doi. org/10.1016/j.anbehav.2005.03.033 
Igelmund P (1987) Morphology, sense organs, and regeneration of the forelegs (whips) of the whip spider Heterophrynus elaphus (Arachnida, Amblypygi). J Morphol 193:75-89

Land MF (1985) The morphology and optics of spider eyes. In: FG Barth (ed) Neurobiology of Arachnids Springer, Heidelberg, pp 53-78

Lehmann T, Melzer RR (2018) Also looking like Limulus? -retinula axons and visual neuropils of Amblypygi (whip spiders). Front Zool 15:1-13. https://doi. org/10.1186/s12983-018-0293-6

Mandal S (2018) How do animals find their way back home? A brief overview of homing behavior with special reference to social Hymenoptera. Insect Soc 65:521-536. https://doi.org/10.1007/s00040-018-0647-2

Menzel R, Leboulle G, Eisenhardt D (2006) Small brains, bright minds. Cell 124(2):237-239. https://doi.org/10.1016/j.cell.2006.01.011

Moller P, Gorner P (1994) Homing by path integration in the spider Agelena labyrinthica Clerck. J Comp Phys 174(2):221-229. https://doi.org/10.1007/ BFo0193788

Murakami H, Tomaru T, Gunji YP (2017) Interaction between path integration and visual orientation during the homing run of fiddler crabs. R Soc Open Sci 4(9):170954-170954. https://doi.org/10.1098/rsos.170954

Norgaard T, Henschel JR, Wehner R (2006) The night-time temporal window of locomotor activity in the Namib Desert long-distance wandering spider, Leucorchestris arenicola. J Comp Physiol A 192:365-372. https://doi. org/10.1007/s00359-005-0072-7

Norgaard T, Nilsson DE, Henschel JR, Garm A, Wehner R (2008) Vision in the nocturnal wandering spider Leucorchestris arenicola (Araneae: Sparassidae) J Exp Biol 211: 816-823. https://doi.org/10.1242/jeb.010546

Ortega-Escobar J (2011) Anterior lateral eyes of Lycosa tarentula (Araneae: Lycosidae) are used during orientation to detect changes in the visual structure of the substratum. J Exp Biol 214:2375-2380

Ortega-Escobar J (2020) Homing in the arachnid taxa Araneae and Amblypygi. Anim Cogn 23:1189-1204. https://doi.org/10.1007/s10071-020-01424-w

Ortega-Escobar J, Munoz-Cuevas A (1999) Anterior median eyes of Lycosa tarentula (Araneae, Lycosidae) detect polarized light: behavioral experiments and electroretinographic analysis. J Arachnol 27(3):663-671

Paulus HF (1979) Eye structure and the monophyly of the arthropoda. In: Gupta AP (ed) Arthropod phylogeny. Van Nostrand Reinhold Company, New York, pp 299-383

Reid SF, Narendra A, Hemmi JM, Zeil J (2011) Polarised skylight and the landmark panorama provide night-active bull ants with compass information during route following. J Exp Biol 214(3):363-370. https://doi.org/10.1242/jeb.049338

Rodriguez RLS, Gamboa ES (2000) Memory of captured prey in three web spiders (Araneae: Araneidae, Linyphiidae, Tetragnathidae). Anim Cogn 3:91-97

Santer RD, Hebets EA (2009) Tactile learning by a whip spider, Phrynus marginemaculatus C.L. Koch (Arachnida, Amblypygi). J Comp Phys A 195(4): 393-399. https://doi.org/10.1007/s00359-009-0417-8 
Santer RD, Hebets EA (2011) The sensory and behavioural biology of whip spiders (Arachnida, Amblypygi). Adv in Insect Phys 41:1-64. https://doi.org/10.1016/ B978-0-12-415919-8.00001-X

Schmid A (1998) Different functions of different eye types in the spider Cupiennius salei. J Exp Biol 201:221-225

Sinakevitch I, Long SM, Gronenberg W (2021) The central nervous system of whip spiders (Amblypygi): large mushroom bodies receive olfactory and visual input. J Comp Neurol 529(7):1-17. https://doi.org/10.1002/cne.25045

Spence AJ, Hebets EA (2007) Anatomy and physiology of giant neurons in the antenniform leg of the amblypygid Phrynus marginemaculatus. J Arachnol 34(3):566-577. https://doi.org/10.1636/S05-53.1

Srinivasan MV (2010) Honey bees as a model for vision, perception, and cognition. Annu Rev Entomol 55:267-284. https://doi.org/10.1146/annurev. ento.010908.164537

Strausfeld NJ (2012) Arthropod Brains: Evolution. Harvard University Press, Cambridge, MA, Functional Elegance and Historical Significance

Strausfeld NJ, Hansen L, Li Y, Gomez RS, Ito K (1998) Evolution, discovery, and interpretations of arthropod mushroom bodies. Learn Mem 5(1-2):11-37

Strausfeld NJ, Sinakevitch I, Brown SM, Farris SM (2009) Ground plan of the insect mushroom body: functional and evolutionary implications. J Comp Neurol 513:265-291. https://doi.org/10.1002/cne.21948

Wehner R (2003) Desert ant navigation: how miniature brains solve complex tasks. J Comp Physiol A 189(8):579-588. https://doi.org/10.1007/ s00359-003-0431-1

Weygoldt P (2000) Whip Spiders (Chelicerata: Amblypygi): their biology, morphology and systematics. Apollo Books, Stenstrup

Wiegmann DD, Hebets EA, Gronenberg W, Graving JM, Bingman VP (2016) Amblypygids: model organisms for the study of arthropod navigation mechanisms in complex environments? Front Behav Neurosci 10:47. https:// doi.org/10.3389/fnbeh.2016.00047

Wiegmann DD, Moore CH, Flesher NR, Harper ED, Keto KR, Hebets EA, Bingman VP (2019) Nocturnal navigation by whip spiders: antenniform legs mediate near-distance olfactory localization of a shelter. Anim Behav 149:45-54. https://doi.org/10.1016/j.anbehav.2019.01.005 
Supplementary Table 1. Experiment 1 association index $(\theta)$ scores for Beginning Session Test Trial (BT) and End Session Test Trial (ET) for each subject, separated by cue type.

Frontal cue

\begin{tabular}{ccccccccccc} 
& \multicolumn{2}{c}{ Day 1 } & \multicolumn{2}{c}{ Day 2 } & \multicolumn{2}{c}{ Day 3 } & \multicolumn{2}{c}{ Day 4 } & \multicolumn{2}{c}{ Day 5 } \\
Subject & BT & ET & BT & ET & BT & ET & BT & ET & BT & ET \\
\hline 1 & -- & 0.86 & 1.00 & 0.66 & 0.55 & 0.92 & 0.69 & 0.91 & 0.63 & 0.23 \\
\hline 2 & -- & 0.43 & 0.12 & 0.49 & 0.19 & 0.48 & 0.35 & 0.55 & 0.63 & 0.51 \\
3 & -- & 1.00 & 0.54 & 0.73 & 1.00 & 0.00 & 1.00 & 0.00 & 1.00 & 1.00 \\
\hline 4 & -- & 0.61 & 0.82 & 0.94 & 0.74 & 0.99 & 0.52 & 0.00 & 0.00 & 0.59 \\
5 & -- & 0.00 & 0.75 & 0.78 & 0.89 & 0.74 & 0.00 & 1.00 & 0.84 & 0.62 \\
6 & -- & 0.51 & 0.59 & 0.54 & 0.70 & 0.72 & 0.63 & 0.57 & 0.71 & 0.65 \\
\hline 7 & -- & 0.78 & 0.96 & 1.00 & 1.00 & 0.00 & 0.57 & 0.15 & 0.59 & 0.84 \\
8 & -- & 1.00 & 0.52 & 0.99 & 0.99 & 1.00 & 0.76 & 0.71 & 0.70 & 0.00 \\
\hline 9 & -- & 0.51 & 0.49 & 0.55 & 0.98 & 0.99 & 0.67 & 0.78 & 1.00 & 1.00 \\
\hline 10 & -- & 0.21 & 0.59 & 0.44 & 0.56 & 0.70 & 1.00 & 0.84 & 0.93 & 0.93 \\
\hline Mean & -- & 0.59 & 0.64 & 0.71 & 0.76 & 0.66 & 0.62 & 0.55 & 0.70 & 0.64
\end{tabular}

Overhead cue

\begin{tabular}{ccccccccccc} 
& \multicolumn{2}{c}{ Day 1 } & \multicolumn{2}{c}{ Day 2 } & \multicolumn{2}{c}{ Day 3 } & \multicolumn{2}{c}{ Day 4 } & \multicolumn{2}{c}{ Day 5 } \\
Subject & BT & ET & BT & ET & BT & ET & BT & ET & BT & ET \\
\hline 1 & -- & 0.82 & 0.49 & 0.57 & 0.27 & 0.53 & 0.00 & 0.67 & 0.56 & 0.80 \\
2 & -- & 0.48 & 0.58 & 0.18 & 0.46 & 0.95 & 0.29 & 0.92 & 1.00 & 0.31 \\
3 & -- & 0.67 & 0.19 & 0.00 & 0.88 & 0.49 & 0.63 & 0.03 & 0.46 & 0.69 \\
4 & -- & 0.69 & 0.19 & 0.68 & 0.55 & 0.67 & 0.16 & 0.48 & 0.57 & 0.68 \\
5 & -- & 0.81 & 0.64 & 0.23 & 1.00 & 0.29 & 1.00 & 0.58 & 0.73 & 0.97 \\
6 & -- & 0.53 & 0.54 & 0.73 & 0.00 & 0.93 & 0.00 & 0.98 & 0.95 & 0.86 \\
7 & -- & 1.00 & 1.00 & 0.99 & 0.41 & 1.00 & 1.00 & 0.00 & 0.68 & 1.00 \\
8 & -- & 0.83 & 0.00 & 0.18 & 0.00 & 1.00 & 0.99 & 0.69 & 0.92 & 1.00 \\
9 & -- & 1.00 & 0.16 & 1.00 & 0.68 & 0.99 & 0.39 & 1.00 & 0.40 & 1.00 \\
10 & -- & 1.00 & 0.58 & 0.96 & 1.00 & 0.68 & 1.00 & 1.00 & 1.00 & 1.00 \\
\hline Mean & -- & 0.78 & 0.44 & 0.55 & 0.53 & 0.75 & 0.54 & 0.64 & 0.73 & 0.83
\end{tabular}


Supplementary Table 2. Experiment 2, Beginning Session Test Trial (BT) and End Session Test Trial (ET) association index ( $\theta)$ scores (averaged across the last three trials) for each subject, separated by pre- and post-occlusion conditions.

\begin{tabular}{ccccc} 
& \multicolumn{2}{c}{ Pre-occlusion } & \multicolumn{2}{c}{ Post-occlusion } \\
Subject & BT & ET & BT & ET \\
\hline 1 & 0.39 & 0.72 & 0.33 & 0.40 \\
2 & 0.76 & 0.81 & 0.60 & 0.71 \\
3 & 0.87 & 0.87 & 0.17 & 0.54 \\
4 & 0.72 & 0.72 & 0.58 & 0.17 \\
\hline Mean & 0.69 & 0.78 & 0.42 & 0.45
\end{tabular}

